\title{
A Study on the On-Line Language Learning Anxiety among Adult Learners
}

\author{
Faizah A Majid, Wan Nurul Elia Haslee Sharil, Johan Eddy Luaran, and Fazyudi Ahmad Nadzri
}

\begin{abstract}
Online learning offers a unique learning environment from the conventional classroom, which provides an area for research that can be used to enlighten practitioners, stakeholders as well as the learners on relevant issues of online learning. This paper intends to examine online language learning anxiety faced by a selected group of adult learners and to determine the relationship between the domains of online language learning anxiety. The 'Online Language Learning Anxiety' (OLLA) inventory was distributed to 57 adult learners who were following a language course online. The data was analyzed using the SPSS package. The findings suggest that, in general, the students were not anxious in learning a language online. However, some areas of concern emerged in the data analysis which includes the learners' cognitive ability in understanding the processes involved in online language learning and their fear in embarking in such courses. Relationships were also found to be strongly significant between learners' readiness and confidence, learners' experience and motivation and learners' attributes and confidence. These pertinent findings may guide online facilitators or lecturers in providing the necessary support to their adult learners in achieving academic success through online learning.
\end{abstract}

Index Terms-OLLA Inventory, Adult Learners, Online Learning, Anxiety.

\section{INTRODUCTION}

Today's era of developing technology has impacted many industries, the education industry included. Many educational institutions now offer online learning as one of their modes of study. The flexibility that online learning offers definitely benefits many adult learners, especially the working adults. Being relatively novel in the education field, online language learning provides research opportunities that are worth exploring. Past researches have concluded findings on the language learning anxiety in traditional language learning classrooms. Nonetheless, not as much researches have been conducted on the online language learning especially one that focuses on the adult learners. Hence, this paper intends to study the anxiety faced by the selected group of adult learners who were taking a language course via online.

\section{A. Problem Statement}

One of the thrusts of the 10th Malaysian Plan aims to develop and sustain world-class human capital. Providing the

Manuscript received March 27, 2012; revised May 11, 2012

Faizah Abd. Majid is with Faculty of Education, Universiti Teknologi MARA, Malaysia (e-mail: faiza404@ salam.uitm.edu.my).

Wan Nurul Elia Haslee Sharil is with Faculty of Education, Universiti Teknologi MARA, Malaysia.

Johan Eddy Luaran is with Faculty of Education, Universiti Teknologi MARA, Malaysia.

Fazyudi Ahmad Nadzri is with Faculty of Education, Universiti Teknologi MARA, Malaysia. existing human capital with opportunities to engage themselves with continuing their education is one of the strategies formed by the government to ensure that the human capital is capable to contribute to the national economic growth (RMK10, 2010). Many universities are now taking the opportunity to provide working adults with a flexible learning experience, such as the Distance Learning Education, Off-Campus Education and Flexible Learning Education. According to Tan Sri Anuwar Ali, the Vice Chancellor of Malaysia Open University, E-learning initiatives in Malaysia are being undertaken mainly by universities, colleges and business enterprises reference [1]. In order to cater to their students' needs of flexibility in learning; many universities incorporate online tutorials into their respective programs. One common compulsory course offered across the universities is the English language course.

In learning a language, emotional responses have a large impact on learners. Reference [2] identified anxiety as one of the emotional responses that has received much attention. Reference [3] elaborated on how adults' anxiety on language learning is heightened when they are required to produce sentences in a language that they know minimally of, as they often view themselves as considerably intelligent and socially-adept individuals. It is interesting to note that their characteristics as adult learners such as their self-concept may pose an unnecessary threat to the adult learners' second or foreign language learning experience. The use of ICT in the adult learners' foreign language learning may further elevate their anxiety in language learning. This has brought to light the need for a research which investigates the adult learners' online language learning anxiety to be conducted.

\section{B. Research Objectives}

The following are the objectives of the study.

1. identify the online language learning anxiety faced by the selected adult learners.

2. determine the relationship between the domains of online language learning anxiety of the selected adult learners.

\section{Research Questions}

Based on the objectives, this study seeks to answer the following research questions.

1. What is the anxiety level faced by the selected adult learners?

2. Are there any significant relationships between the domains of online language learning anxiety?

\section{LITERATURE REVIEW}

\section{A. Adult Learners}

References [4], [5] and [6] are some of the advocators of 
adult education. They have defined adult learners as students who enter or re-enter education with special characteristics that differentiate them from other conventional learners. Adult learners are also associated with three unique characteristics which encompass their self-concept, role of experience in their learning process and learning readiness. It is also common to categorize adult learners as those who have other role(s) than that of a student. Thus, adult learners may also be an employer or an employee besides being a student. With these different roles comes a variety of responsibilities which require them to become multi-taskers. Reference [7] added on by stating the rich experience that the adult learners have had in their lives help to shape their behavior and thinking. In other words, adult learners are typically associated with a community of learners who have had more life experience as compared to the conventional learners, which may affect the way they learn when they re-enter a learning institution to further their studies. However, these experiences may become a facilitator or a hindrance to learning for the adult learners [4], [6], [8]. Additionally, according to Reference [9], retrieved from http://theelearningcoach.com/learning/characteristics-of-adu lt-learners, “... Through experience, adults may fear a subject, have anxiety about a subject or feel anger about forced changes in job responsibilities or policies. These emotions can interfere with the learning process". The decision to further their studies is often based on specific reasons; which are usually work-driven [7].Thus, an adult would normally decide to further their studies when it provides them with opportunities to develop their profession or career.

Given the unique characteristics of the adult learners, it is imperative for adult educators or trainers to realize that they need to understand 'andragogy', a term coined by [4], [10] outlined six andragogic principles which educators need to take into consideration when facilitating their adult learners. These six principles include what the learners need to know, self-directed learning, prior experience, readiness to learn, orientation in learning, and motivation to learn. First, the adult learners need to know the 'What', 'How' and 'Why' of learning. The learners need to know what learning will occur; why they are learning and how will they learn. Secondly, the adult learners are self-directed, where they are able to take charge of their own learning. However, reference [8] refuted this by stating some adults may want to be treated as children when they re-enter education. Thirdly, the experiences that the adult learners bring with them will definitely impact their learning. Nevertheless, reference [4] added on by mentioning that the adult learners may also form habits that will not facilitate their learning. Fourth, as mentioned by [7], adult learners further their studies when they are ready to learn, with very specific reasons. Fifth, the best orientation in learning for the adult learners is problem-solving because they will be able to relate it with their life experiences. Finally, the motivation level of the adult learners is significantly higher as they will be motivated by the specific reasons that drove them to re-enter the educational institutions.

\section{B. Online Learning}

Online learning has become one of the new methods to disseminate information and education. Due to the rapid development in technology, many universities are now able to offer a mode of learning that advocates flexibility for their learners which is the online learning. In Malaysia, most universities now offer online learning courses with different structures to cater to the needs of adult learners who are usually employees with limited time to come for conventional classes.

Reference [11] outlined the typology of Internet uses in distance education. Type $\mathrm{I}$ is the Traditional Distance Learning Supplemented with Internet Activities, Type II is Computer Conferencing and Type III is Virtual Courses and Institutions. These three different types of Internet uses differ in the rapidity of Internet usage in learning. For Type I, the learners use the Internet to supplement the discussion conducted in class by using email exchanges, looking for research material online and could also include online discussion. For Type II, the Internet becomes the medium of instruction, where students might still have printed materials; they will converse through the Internet with their other peers. Type III internet usage directs the learners to web-based courses, where the learners are required to be more self-directed as compared to Type I and Type II.

One of the challenges of Vision 2020 is to create a society which is scientifically and technologically advanced. The provision of online learning in the Malaysian learning institutions is seen as an effort towards achieving the targeted scientific and advanced society. Through online learning, access to education is no longer an issue. In line with the need for k-workers and quality human capital, online learning is the answer to many working adults who intend to pursue their studies. The presence of e-learning and e-learners promises the foundation of a knowledge society where information and resources is easily available through the web and to the masses.

However, the success of an online program will depend on the learner's commitment and readiness towards the program. As stated by reference [1], “... Online learning requires a very high degree of self-motivation which is found to be lacking among our learners. Learners find it difficult to migrate from the traditional learning mode to the new e-learning mode".

Online learning provides a platform for those who are discipline and who is an independent learner, and who can employ a variety of strategies to construct their own knowledge.

\section{Online Language Learning}

The development of computer usage in language learning started with the computer assisted language learning (CALL) movement in the 1970s. The advancement of the internet and the world wide web (WWW) has brought in online learning. According to reference [12], the internet could encourage more independent and active learning among students. Reference [13] posits that the quality of teaching and learning could easily be enhanced with this technology. Reference [14] further states that online learning could provide major learning environments for distance education or to supplement face-to-face discussion.

The rapid development of e-learning has encouraged language classes to also include language learning activities through the internet. It is believed that online language learning could promote student critical thinking, knowledge 
construction and language learning autonomy [15]-[17] point out that well structured and appropriately facilitated online learning can provide an environment that allows the immediate application of new information to learners' personal and professional lives. Additionally, online learning is more flexible compared to face to face communication as in the traditional classrooms. This is due to the fact that they provide time to reflect and think and allow both introverted and extroverted students to be involved in online discussions

However, despite the growing interest in the application of online learning in language classes, there are still teething issues that need to be addressed. Reference [18] in his article discussed several aspects of learning that will be affected with the incorporation of technology. These aspects included individualization, motivation, experiential learning and greater interaction among the learners. Reference [18] also discussed the teachers' barriers to the use of computer-assisted language learning also include availability of hardware and software, lack of theoretical and technical knowledge, and acceptance of technology. Interestingly, although Lee discussed this in terms of CALL, these barriers are similar to those faced by online educators.

\section{Learning Anxiety}

Anxiety is the "subjective feeling of tension, apprehension, nervousness, and worry associated with an arousal of the automatic nervous system" [19] as cited in Reference [3]. According to Horwitz and Young (1991), there are two approaches in describing language anxiety. First, anxiety may be viewed as a "manifestation of other more general anxiety" [20]. Second, language anxiety could also be viewed as "a distinctive form of anxiety expressed in response to language learning" (ibid.).

Reference [21] in reference [7] claims that the affective domain has the most significant relationship when dealing with anxiety. Affective variables have often been seen as the opposite of cognitive variables. In other words, affective variables are everything that impinges on language learning that is not related to cognition. It is also proposed that self-perceptions, beliefs, feelings, and behaviors related to classroom language learning be part of the basis when investigating the anxiety.

Reference [20] categorized potential sources of learners' anxiety in the foreign language classroom into six types: personal and interpersonal anxieties (e.g., self-esteem, communication apprehension); learner beliefs about language learning; instructor beliefs about language teaching; instructor-learner interactions (e.g., teachers' harsh manner of correcting student mistakes); classroom procedures (e.g., speaking in front of peers); and testing. Reference [3] suggested that students' fear of negative evaluation is influenced by the nature of the foreign language classroom, where student performances are continually evaluated by the only fluent speaker, the teacher. Students may also be acutely sensitive to the real or imagined evaluations of their peers.

\section{RESEARCH METHODOLOGY}

\section{A. Research Design}

This study sought to identify the online language learning anxiety faced by the selected adult learners. Additionally, it aims to determine the relationship between the different domains of the adult learners' online language learning anxiety. The quantitative research method was used in this study. Quantitative research is a scientific method of investigation to look at relationships between variables studied. In most of quantitative research method, descriptive or inferential statistical method is applied to help with the data analysis. Additionally, the choice of a quantitative research design was influenced by Harvey (2002) as cited in Reference [22]. According to him, quantitative research provides data, which is easy to sort and classify. This in turn could enable the researcher to measure the data in an objective way, which is the data could be accurately described due to the set of rules or formulae and procedures prescribed in any quantitative data analysis. Consequently, the data could be interpreted unambiguously. To serve its purpose, a survey was seen as most suitable for the present study.

\section{B. Population and Sampling}

The selected adult learners involved in the study were a group of in-service adult learners who were doing their language course in a bachelor's program which was offered in the e-learning mode in one of the public universities in Malaysia. The population of the students enrolled in the program during the time the study was conducted was 140 . For the purpose of sampling, a total of 57 adult learners were identified to take part in the study. Upon briefing, all of the identified adult learners agreed to participate. They were given a set of questionnaire to complete. The researchers were present during the completion of the questionnaire which took place in a classroom during one of their scheduled monthly class seminars. All completed questionnaires were collected immediately in order to ensure $100 \%$ return rate.

\section{The Instrument}

The questionnaire consists of two sections. Section A is on respondents' demographic profile while Section B is on the online language learning anxiety. The online language learning anxiety (OLLA) which was developed by reference [7] was adopted in Section B of the questionnaire. A pilot study was carried out prior to the actual administration of the questionnaire to the target group. The pilot study was conducted on 30 UiTM E-PJJ students. The test retest method to ensure the reliability of each statement was carried out. It is critical to carry out the pilot study in order to test the respondents' understanding of the items and statements in the questionnaire. Thus this helped to test the reliability of each and every statement. The pilot study identified the language and the level of negativity of the statements answered. The pilot study would thus ensure that the statements in the questionnaire could be easily understood and help to produce reliable data and answers to the study. After some modifications and omission of the negative items, test-retest reliability for students is quite high (.83) and the alpha coefficient is .82 . This is a comfortable value which enabled the researchers to proceed administering the questionnaire to the respondents.

\section{The Online Language Learning Anxiety (OLLA) Questionnaire}

On-line Language Learning Anxiety (OLLA) was initially 
developed by adapting [21] 'Language Learning Anxiety Questionnaire'. It consists of 31 statements reflecting the respondents' perception of their on-line language learning. The 31 statements correspond to seven different domains. Likert scale of 1 to 5 was used with 1 as strongly disagree and 5 , strongly agree.

Domain 1 is about the 'attributes of on-line English language learning' and corresponds to questions on the negative perception that the respondents have towards on-line language learning. Domain 2 is about the 'motivation for on-line English language learning'. The statements help the respondents to identify their positive attitude towards on-line language learning program. The third domain is about the 'confidence in on-line English language learning' where the statements enable the respondents to gauge their confidence level when approaching their on-line language learning classes.

The fourth domain is on 'Experiencing on-line English language learning'. This domain helps to identify how comfortable the respondents are in online language learning. Domain five is about the 'fear of the on-line English language learning' which helps the respondents to identify their fear in the on-line language learning classes. Domain 6 looks at the 'cognitive ability' of the respondents in on-line English language learning. Finally, domain seven is on the 'readiness in on-line English language learning', which examined the learners' perception of their readiness to embark on the online language learning experience.

\section{FINDINGS}

Discussions on the findings are guided by the research questions. The following is the discussion on the findings which provide answers to the first research question: What is the anxiety level faced by the selected adult learners?

The discussion is based on the following table.

TABLE I: THE ADULT LEARNERS’ ONLINE LANGUAGE LEARNING

\begin{tabular}{lcc}
\multicolumn{3}{c}{ ANXIETIES } \\
\hline Attributes & Mean & Std. Deviation \\
Motivation & 3.0706 & .38581 \\
Confidence & 3.5556 & .54311 \\
Experiencing & 3.1312 & .36996 \\
Fear & 3.6564 & .64011 \\
Cognitive & 2.9298 & .71752 \\
Readiness & 2.6433 & .53400 \\
Valid N (listwise) & 3.3684 & .47506
\end{tabular}

From Table I, it can be concluded that generally, the learners' did not have a high level of online language learning anxiety. Based on the table, the learners were the least anxious on the fourth domain, which described the learners' comfortability in online language learning (mean $=3.65, \mathrm{SD}$ $=.64$ ). In other words, the learners indicated positive experiences during their online language learning. This finding was also reflected in domain two, which examined the learners' motivation in online language learning (mean = $3.56, \mathrm{SD}=.54)$. However, although the learners were found to be motivated and positive towards learning English language online, the findings on their confidence in embarking in such course were not as high (mean $=3.13$, SD $=.36$ ). From Table 1, it was also found that the learners were most anxious on domain six, which investigated the learners' cognitive ability (mean $=2.64, \mathrm{SD}=.53$ ). The findings indicated that the learners, at times; had difficulties in understanding the process involved in online language learning and they might become more confused as they progressed learning English language online. This might was contributed by learners' anxiousness in domain 5- fear of online language learning $($ mean $=2.93, \mathrm{SD}=.72$ ).

Adult learners' are often associated with special characteristics that are different from conventional learners references [4], [5] and [8]. [7] stated that the adult learners' decisions to further their studies are often based on specific reasons; usually that provides them opportunities to develop their profession or career. Having the chance to improve their professional positions could be a major motivator in embarking on a course; which in turn, explained why the selected learners in this study was found to be motivated and indicated positive learning experiences throughout their course. The third and the fourth findings correlates with reference [7] who proposed that adult learners brings in their rich life experiences with them into the classroom. References [4], [5] and [8] claimed that these experiences could become a facilitator or a hindrance in the adult learners' learning. Based on the findings, the selected learners were found to struggle under the confidence and cognitive ability domains. Learning the language online is a new territory for the adult learners. The learning environment was different from how they used to learn. Not having much experience in the online learning domain could have contributed to the learners' difficulties in terms of their fear of online language learning and cognitive abilities. This claim is further supported by [1] who posits that "...Learners find it difficult to migrate from the traditional learning mode to the new e-learning mode." The close mean scores between the adult learners' confidence $(3.13, \mathrm{SD}=.36)$ and readiness $(3.36, \mathrm{SD}$ $=.47$ ) in this study further confirms this.

Table 2 represents the analysis of the findings for the second research question, which investigated the relationships between the domains of online language learning anxiety among the selected adult learners. There are three significant positive relationships that can be inferred from Table 2. The first significant positive relationship was drawn from the readiness domain with the confidence domain $(r=.98, p<.05)$. This suggests that when the learners are ready to embark on the online language learning, their confidence level will most likely increase. Being ready includes the students' pre-conceived idea about the online language learning experience. In shaping this particular perception, it would require the learners to be exposed to what online language learning is all about, which could include readings on online language learning, asking friends or colleagues about online language learning and being familiar with the online language learning context. Once these are done, the learners may perceive themselves as being ready, thus increasing their confidence level.

Table II also indicated a strong positive relationship between the experience and the motivation domains $(\mathrm{r}=.77$, $p<.05)$. This indicates that the more positive the learners' experience in online language learning is, the more motivated 
they become in their online language learning. The experience domain included questions to investigate the challenges that the learners faced, their perception of the experience that they have had, and their prediction on their ability in the future, based on the current condition on their online language learning experience. The finding suggests that if these conditions are positive, chances are, they would be more motivated in participating in online language learning.

\begin{tabular}{|c|c|c|c|c|c|c|c|}
\hline & & Attributes & Confidence & Experience & Readiness & Motivation & Cognitive \\
\hline \multirow{3}{*}{ Attributes } & Pearson Correlation & 1 & $.724^{* *}$ & .233 & .196 & .241 & $.559^{* *}$ \\
\hline & Sig. (2-tailed) & & .000 & .081 & .145 & .071 & .000 \\
\hline & $\mathrm{N}$ & 57 & 57 & 57 & 57 & 57 & 57 \\
\hline \multirow{3}{*}{ Confidence } & Pearson Correlation & $.724^{* *}$ & 1 & .134 & -.003 & .158 & $.573^{* *}$ \\
\hline & Sig. (2-tailed) & .000 & & .322 & .980 & .241 & .000 \\
\hline & $\mathrm{N}$ & 57 & 57 & 57 & 57 & 57 & 57 \\
\hline \multirow{3}{*}{ Experience } & Pearson Correlation & .233 & .134 & 1 & $.367^{* *}$ & $.767^{* *}$ & .013 \\
\hline & Sig. (2-tailed) & .081 & .322 & & .005 & .000 & .922 \\
\hline & $\mathrm{N}$ & 57 & 57 & 57 & 57 & 57 & 57 \\
\hline \multirow{3}{*}{ Readiness } & Pearson Correlation & .196 & -.003 & $.367^{* *}$ & 1 & .131 & .244 \\
\hline & Sig. (2-tailed) & .145 & .980 & .005 & & .332 & .068 \\
\hline & $\mathrm{N}$ & 57 & 57 & 57 & 57 & 57 & 57 \\
\hline \multirow{3}{*}{ Motivation } & Pearson Correlation & .241 & .158 & $.767^{* *}$ & .131 & 1 & .057 \\
\hline & Sig. (2-tailed) & .071 & .241 & .000 & .332 & & .672 \\
\hline & $\mathrm{N}$ & 57 & 57 & 57 & 57 & 57 & 57 \\
\hline \multirow{3}{*}{ Cognitive } & Pearson Correlation & $.559^{* *}$ & $.573^{* *}$ & .013 & .244 & .057 & 1 \\
\hline & Sig. (2-tailed) & .000 & .000 & .922 & .068 & .672 & \\
\hline & $\mathrm{N}$ & 57 & 57 & 57 & 57 & 57 & 57 \\
\hline
\end{tabular}

The final significant positive relationship can be drawn from the attributes and confidence domains $(r=.72, p<.05)$. The attributes domain examined the perceptions of the learners towards the attributes of online language learning. The findings suggests that the learners' confidence level would likely increase if they are more positive with the online language learning attributes. This finding also indicates the importance of perception towards the improvement of the confidence level. In other words, the more positive they are towards the attributes of online language learning, the more confident they could be.

\section{DisCUSSION AND PEDAGOGICAL IMPLICATIONS}

The first finding in this study suggests that although the adult learners were generally not anxious in learning a language online, two domains from the inventory yielded some areas of concern. The domains involved learners' cognitive ability and their fear in embarking in such courses. The findings suggest that the learners at times, had difficulties understanding the process involved in online language learning and as they progressed, they became more confused. The other domain that is alarming is the learners' readiness in enrolling such courses. The findings suggest that the learners were apprehensive in the online learning method, which could be contributed by the unfamiliarity of the learning context and this may become intimidating to the learners.

In trying to reduce these domains of anxiety, the learning institutions and the online facilitators play significant roles. Learners' anxiety on cognitive abilities in understanding the online language learning process may be reduced with sufficient support given by the online facilitators. The nature of online learning is different from the conventional classroom. Therefore, online facilitators need to find other avenues in providing support as they rarely see these online learners face-to-face [1] claims, “...Realizing that we are in the transition period between the traditional and e-learning modes, we propose that a blended approach be adopted." In this instance, the blended approach may include the combination of several different delivery methods such as face-to-face interactions, self-paced and individualized learning and online interactions. The educators too could be more supportive to their online adult learners by creating a discussion board in which the participants (i.e. the learners in turn, would require the educators to have effective questioning strategies in prompting the active discussions among the participants. At this juncture, the six types of Socratic Questions may be referred.

In addressing the learners' readiness to enroll in such courses, it is pertinent for the learning institutions that offer online courses to conduct rigorous induction seminars, courses and hands-on workshops to explain the structure of the program as well as how the online system works. Providing the learners with handbooks could be a start to assist them in overcoming their anxiety, but in skill acquisition, the best way to learn would be experiential learning [23]. In doing this, the learners' anxiety on the readiness domain might be reduced as they uncover the unfamiliar contexts of the online learning contexts.

The second finding draws the relationships between the anxiety domains. Three significant positive relationships were indicated from the findings. The first significant relationship was drawn from the readiness and confidence domains which signifies the more ready the learners are in 
embarking in such courses, the more confident they become in their learning. This brings us to the suggestion made by reference [7], who suggested that the lack of exposure towards online language learning programs could contribute to the learners' anxiety on the confidence domain. When the learners are not ready, which could be drawn from the lack of exposure, their confidence level will definitely be affected. Reference [7] further put forth similar suggestions as the ones made above, which is to provide the learners with sufficient training and guidance. This may help to reduce the learners' anxiety on their readiness, which may in turn, boost their confidence level.

The second significant positive relationship was found between the experience and the motivation domains; which suggested the more experience they get from the online language learning courses, the more motivated the adult learners become in their learning. As the learners progress in their online learning, the learners would start to uncover elements of the online learning that they find enjoyable or unenjoyable. At this juncture, it is important for educational institutions and online facilitators to ensure that online learning becomes an enjoyable one by providing them the support that they need-be it in terms of content, motivational or technical needs. Reference [23] experiential learning theory could be taken as a point of reference, which suggested that teachers should begin by bringing out the learners' beliefs and theories, examining and testing them, then integrating the new, more refined ideas into the learners' belief systems. This means teachers should not just to 'implant new ideas' but to also review the learners' existing beliefs. The existing beliefs can be disposed of, or modified, by the integration of new ideas presented by the educator.

The final significant positive relationship was found between the learners' attributes towards online language learning and the confidence domain; which means the more positive their perceptions are towards the online language learning, the more confident they will be in their learning. The attributes domain measures the learners' perceptions towards the online language learning, which included investigations on how they view the online learning concept. In improving the learners' perceptions on the online learning courses, it will be a challenging task for online facilitators and educational institutions as perceptions are not easily modified. Fostering a better perception could be done by ensuring that the learners are comfortable with the facilities and support provided by both educational institutions and online facilitators. In other words, educational institutions and the online facilitators should not further affirm the negative perceptions that these learners have, by making facilities and support available for the learners.

\section{CONCLUSION}

This paper has addressed several issues regarding adult learners' anxiety in online language learning. Findings of the research suggest that the adult learners were mostly anxious about their cognitive ability and readiness in taking up online language learning courses. The research also found that there were three significant positive relationships between readiness and confidence, experience and motivation as well as between attributes and confidence. The paper has also identified some implications of these findings for the educational institutions and the online facilitators to take into consideration when delivering the online language learning courses, to reduce the adult learners' anxiety towards online language learning, which in turn, empower them to take charge of their own learning.

\section{REFERENCES}

[1] A. Anuwar,. (2012) Issues and challenges in implementing e-learning in Malaysia. [Online]. Available: http://eprints.oum.edu.my/145/1/issues_and_challenges.pdf.

[2] Hedge, T., Teaching and Learning in the Language Classroom. London: Oxford University Press, 2001.

[3] E. L. Horwitz, M. B. Horwitz, and J. A. Cope, "Foreign Language Classroom Anxiety," The Modern Language Journal, vol. 70(2), pp. 125-131, 1986.

[4] M. Knowles, Adult learners: A neglected species: Kogan Page, 1990.

[5] R. Riche. Designing instructions for the adult learners: Systemic training theory and practice. London: Kogan Page, 1992.

[6] A. Rogers, Teaching Adults. London: OUP, 2002

[7] A. M. Faizah, O. Siti Hawa, and R. Khairezan, "Adult Learners' Characteristics And Their Anxiety In On-Line Language Learning," Innovation and Intervention in ELT: Pathways and Practices, UPM Press, 2007.

[8] A. Hanson, "The Search For A Seperate Theory Of Adult Learning:Does Anyone Really Need Andragogy?" in Boundaries of Adult Learning, Edwards R., Hanson A., and Raggatt P. (Eds.), London: Routledge, 1996.

[9] J. Malame, (2012) on The elearning coach. [Online]. Available: http://theelearningcoach.com/elearning_design/top-10-of-2010

[10] M. S. Knowles, E. F Holton, and R. A. Swanson, The Adult Learner, Texas: Gulf, 1998.

[11] D. V. Eastmond, "Adult Learners and Internet Based Distance Education”, New Directions for Adult and Continuing Education, vol. 78, pp. 33-41, 1998.

[12] J. McKimm, C. Jolie, and P. Cantillon, Web base learning. BMJ, 2003.

[13] M. Groves, and J. O'Donoghue, "Reflections of Students in Their Use of Asynchronous Online Seminars," Educational Technology \& Society, vol. 12(3), pp. 143-149, 2009.

[14] D. M. Jacobsen, Learning Technology in Continuing Professional Development: The Galileo Network. New York, NY: The Edwin Mellen Press, 2006.

[15] C. P. Lim and C. S. Chai, "An activity-theoretical approach to research of ICT integration in Singapore schools: orienting activities and learner autonomy”, Computers \& Education, vol. 43, no. 3, pp. 215-236, 2004

[16] R. M. Marra, J. L. Moore, and A. K. Klimczak, , "Content analysis of online discussion forums: a comparative analysis of protocols," Educational Technology Research and Development, vol. 52(2), pp. 23-40, 2004

[17] T. Smith, (2001) on Asynchronous discussions: Importance, design, facilitation, and evaluation. [Online]. Available: http://www.ion.illinois.edu/pointers/ 2002_11/pagel .html

[18] K. Lee, "English Teachers' Barriers to the Use of Computer-assisted Language Learning”. The Internet TESL Journal, vol. 6(12), 2000.

[19] C. D. Spielberger, Manual for the State-Trait Anxiety Inventory. Palo Alto, CA: Consulting Psychologists Press, 1983.

[20] E. K. Horwitz, and D. J. Young, Language Anxiety: From Theory And Research To Classroom Implications, Englewood Cliffs, N.J: Prentice Hall. pp. 27-36, 1991.

[21] T. Scovel," "The Effect of Affect on Foreign Language Learning: A Review of the Anxiety Research", Language Learning, vol. 28, pp. 129-142, 1978.

[22] R. O'neill, (2006) on The advantages and disadvantages of qualitative and quantitative research methods. [Online]. Available: http://www.roboneill.co.uk/papers/research_methods.htm

[23] D. A. Kolb, Experiential Learning-Experience as the Source of Learning and Development, New Jersey: Prentice Hall, 1984. 